\title{
Re-sequencing of the APOAl promoter region and the genetic association of the -75G > A polymorphism with increased cholesterol and low density lipoprotein levels among a sample of the Kuwaiti population
}

\author{
Suzanne A Al-Bustan ${ }^{1 *}$, Ahmad E Al-Serri², Babitha G Annice ${ }^{1}$, Majed A Alnaqeeb ${ }^{1}$ and Ghada A Ebrahim ${ }^{3}$
}

\begin{abstract}
Background: APOAl, a member of the APOAI/CIII/IVN gene cluster on chromosome 11q23-24, encodes a major protein component of HDL that has been associated with serum lipid levels. The aim of this study was to determine the genetic association of polymorphisms in the APOAI promoter region with plasma lipid levels in a cohort of healthy Kuwaiti volunteers.

Methods: A 435 bp region of the APOAl promoter was analyzed by re-sequencing in 549 Kuwaiti samples. DNA was extracted from blood taken from 549 healthy Kuwaiti volunteers who had fasted for the previous $12 \mathrm{~h}$. Univariate and multivariate analysis was used to determine allele association with serum lipid levels.

Results: The target sequence included a partial segment of the promoter region, 5'UTR and exon 1 located between nucleotides -141 to +294 upstream of the APOAI gene on chromosome 11. No novel single nucleotide polymorphisms (SNPs) were observed. The sequences obtained were deposited with the NCBI GenBank with accession number [GenBank: JX438706]. The allelic frequencies for the three SNPs were as follows: APOAI rs670G $=0.807 ;$ rs5069C $=0.964 ;$ rs 1799837G $=0.997$ and found to be in HWE. A significant association $(p<0.05)$ was observed for the APOAI rs670 polymorphism with increased serum LDL-C. Multivariate analysis showed that APOAI rs670 was an independent predictive factor when controlling for age, sex and BMI for both LDL-C (OR: 1.66, $p=0.014$ ) and TC (OR: 1.77, $p=0.006$ ) levels.

Conclusion: This study is the first to report sequence analysis of the APOAI promoter in an Arab population. The unexpected positive association found between the APOAI rs670 polymorphism and increased levels of LDL-C and TC may be due to linkage disequilibrium with other polymorphisms in candidate and neighboring genes known to be associated with lipid metabolism and transport.
\end{abstract}

Keywords: APOAl, Polymorphism, LDL, Re-sequencing, SNPs, Arabs, Kuwait

\footnotetext{
* Correspondence: s.albustan@ku.edu.kw

'Department of Biological Sciences, Faculty of Science, Kuwait University, PO Box 5069, Safat 13060, Kuwait

Full list of author information is available at the end of the article
} 


\section{Background}

Plasma lipids have an essential role in several metabolic systems including the endocrine, nervous and circulatory systems [1] and their levels are influenced by lifestyle factors such as diet, physical activity and smoking, as well as genetic factors [2,3]. Variation in plasma lipid levels, commonly referred to as dyslipidemia, is characterized by increased total cholesterol (TC), triglycerides (TG), and low-density lipoprotein (LDL) as well as decreased high-density-lipoprotein (HDL). Dyslipiemia is commonly present among people whose diet is high in fat and low in fiber [4]. Twin and family studies have shown that plasma lipid levels are particularly influenced by genetic factors with a widely reported variation of heritability ranging from $40-60 \%$ [2]. Since lipid levels may be under genetic control [2,5], the identification and characterization of genetic variants associated with plasma concentrations may provide some insight into the genotype-phenotype relationship [3] and allow for lifestyle adjustments to improve health. Several reports, including the Genome Wide Association Studies, have attempted to elucidate the genetic and molecular mechanisms of dyslipidemia based on measurements of plasma lipids and have identified a limited number of candidate genes and pathways relevant to lipid metabolism and/or transport [3,6-11].

The APOAI gene encodes a major protein component of HDL that forms a structural part of the lipoprotein particles with a primary function in signaling and targeting lipoproteins in the reverse cholesterol transport from peripheral tissues to the liver for its excretion. It is also an important cofactor for lecithin cholesterolacyltransferase (LCAT) which catalyzes the formation of plasma cholesterol esters in the plasma [12] for their transfer from peripheral tissues. The gene encodes a 267 amino acid polypeptide, synthesized in the liver and intestine, where it undergoes intracellular cleavage followed by extracellular proteolysis yielding the mature 243 amino acid apoA-I polypeptide [13]. The APOAI gene is part of the APOAI/CIII/IV/V gene cluster located in chromosome 11q23-24 spanning over $20 \mathrm{~Kb}$ [14]. This gene cluster has been shown to have a relationship to dyslipidemia with different polymorphisms in each gene having varying degrees of association with different plasma lipids. There is much controversy regarding the association of specific reported single nucleotide polymorphisms (SNPs) at the APOAI locus with dyslipidemia. Several SNPs have been documented that are reported to be associated to HDL and cholesterol levels, including g.-75G > A (rs670), g. + 83C > T (rs5069) and g. + 84G > A (rs1799837). The rs670 variation has been reported to enhance promoter function [15] with the minor allele (A) being associated with abnormal variation in lipid levels in several populations [11,16-21]. In contrast, studies have reported this variant having decreased promoter activity [22], while others showed no effect on promoter activity [23]. In addition, several studies have reported different mutations in the coding region of the gene to be associated with reduced levels of HDL-C [8,13,24-27]. Another variation slightly further downstream is a $\mathrm{C}$ to a $\mathrm{T}$ transition at position rs5069 which occurs simultaneously or independently of a second transition from a $\mathrm{G}$ to an A at position rs1799837 $[15,17,19,28,29]$. The minor allele $\mathrm{T}$ for rs5069 is associated with increased HDL-C $[15-17,19,29,30]$ and decreased TG levels [18] while the minor allele A for rs1799837 appears to be associated with HDL-C levels [15,27] as well as with heart disease [27].

The exact polymorphisms responsible for the apparent influence of this locus on HDL levels in particular are not fully elucidated [31] and very few studies have found an association with other lipid levels. It is well established that differences among populations in the relative frequency of 'susceptibility genotypes' or environmental exposure may contribute to the utility of a genotype for predicting a trait within a particular population $[32,33]$. These kinds of genetic association studies with regards to APOAI have not been investigated in the Kuwaiti population and there are only limited reports on other Arab populations [34,35]. Traditionally, the Kuwaiti/Arab diet is high in fat, raising the risk factors of cardiovascular diseases such as diabetes mellitus, dyslipidemia, obesity and hypertension. Studies on the lipid profiles of the Kuwaiti population [36] have reported a higher prevalence of hypercholesterolemia in women (36.6\%) than in men $(30.2 \%)$ with hypertriglyceridemia being higher in men (44.1\%) than in women (33.8\%) The Kuwaiti population also ranks high worldwide in prevalence of overweight (80.4\%), obesity $(47.5 \%)$, and metabolic syndrome (36.2\%) [37]. It is hypothesized that the reported high frequencies of dyslipidemia and their association to metabolic syndrome are the outcome of an interaction between established risk factors and genetic polymorphisms. The objective of the present study was to assess the association of several genetic polymorphisms in the promoter region of the APOAI gene locus found by re-sequencing, with variation in lipid levels, among a cohort of the healthy Kuwaiti population.

\section{Methods}

\section{Study population}

This study was undertaken within the guidelines set by the Declaration of Helsinki and was reviewed and approved by the Local Ethical Committee at Kuwait University. The cohort in this study $(\mathrm{n}=549)$ included 213 male and 336 female ethnic Kuwaiti nationals with ages ranging from 18 to $72 \mathrm{y}$ with a mean of $29 \mathrm{y}( \pm 0.54$ SEM). Whole blood was collected, with informed consent, 
from healthy volunteers undergoing a routine visit at a regional polyclinic or at one of the major hospitals in Kuwait. The randomized sample included 154 individuals with increased levels of serum TC $(>5.17 \mathrm{mmol} / \mathrm{L}), 11$ with increased TG levels $(>2.19 \mathrm{mmol} / \mathrm{L}), 85$ with increased levels of LDL-C $(>3.2 \mathrm{mmol} / \mathrm{L})$ and 113 with abnormal HDL-C levels $(\leq 1.3 \mathrm{mmol} / \mathrm{L})$. For each individual, several phenotypic variables including BMI (Table 1) and family history of hypercholesterolemia, hypertension, diabetes and heart disease were recorded.

\section{Biochemical analysis and diagnostic criteria}

A venous blood sample of $11 \mathrm{ml}$ was obtained from all individuals who had previously fasted for at least $12 \mathrm{~h}$. About $3 \mathrm{ml}$ was used to determine serum lipid levels and $5 \mathrm{ml}$ were transferred to tubes with anti-coagulant and used to extract genomic DNA. The levels of serum TC, TG, HDL-C, and LDL-C in each sample were determined by enzymatic methods with commercially available kits and performed on a UniCel DxC 800 Synchron Clinical System from Beckman Coulter (USA) in the Clinical Chemistry facility at Al-Amiri Hospital. Individuals were considered normal if their serum values for TC, TG, HDL-C and LDL-C fell within the Kuwaiti population reference range of 3.0-5.17, 0.40-2.19, 0.91-1.3 and $1.8-3.2 \mathrm{mmol} / \mathrm{L}$, respectively. The cohort was divided into two groups normal and abnormal by each lipid parameter. Normal weight, overweight and obesity were defined as a $\mathrm{BMI}<24,24-28$, and $>28 \mathrm{~kg} / \mathrm{m}^{2}$, respectively.

\section{Re-sequencing of the partial region in the promoter/exon 1 of the APOAl gene locus}

A 435 bp region of the APOAI promoter was analyzed by direct sequencing in 549 Kuwaiti samples. Genomic DNA was extracted from $5 \mathrm{ml}$ of whole blood using a proteinase $\mathrm{K}$ digestion and salting out extraction method as previously described by Miller et al. [38]. The purified DNA samples were first subjected to PCR amplification

\begin{tabular}{ll}
$\begin{array}{l}\text { Table } \mathbf{1} \text { Demographic and clinical features of } \\
\text { study cohort }\end{array}$ \\
\hline Parameters \\
\hline Sex (Males, Females) & $38.8 \%, 61.2 \%$ \\
Age (yr) & $29 \pm 0.54$ \\
BMI & $27 \pm 0.29$ \\
Cholesterol (mmol/L) & $4.6 \pm 0.03$ \\
LDL (mmol/L) & $3.05 \pm 0.03$ \\
HDL (mmol/L) & $1.18 \pm 0.01$ \\
Triglyceride (mmol/L) & $0.92 \pm 0.03$ \\
Positive family history of hypercholesterolemia & $32.42 \%$ \\
Positive family history of heart disease & $33.88 \%$ \\
\hline
\end{tabular}

Data shown as means \pm SEM or for the BMI and lipid levels except for TG where the median and inter-quartile range is represented. of the target sequence in the promoter region with the following primers: (forward) 5'-AGGGACAGAGCTGA TCCTTGAACTCTT AAG $-3^{\prime}$ and (reverse) $5^{\prime}$-TTAGG GGACACCTAC CCGTCAGGAAGAGCA-3' using Fast Amplitaq Gold PCR Master Mix $1.25 \mathrm{ml}$ in an Applied Biosystems Fast thermal cycler (Version 1.01, Life Technologies). An initial denaturation step of $95^{\circ} \mathrm{C}$ for $10 \mathrm{sec}$ was followed by 35 cycles of denaturation at $94^{\circ} \mathrm{C}$ for $10 \mathrm{sec}, 55^{\circ} \mathrm{C}$ for $25 \mathrm{sec}$, a final extension of $72^{\circ} \mathrm{C}$ for $30 \mathrm{sec}$ and a subsequent hold at $4{ }^{\circ} \mathrm{C}$. The amplified PCR products $(10 \mu \mathrm{l})$ were then purified with a Nucleospin column followed by formaldehyde denaturation. Sequencing was performed twice in two separate reactions, one with the forward primer and the other with the reverse primer for all samples in Fast thermal cycler (Life Technologies, Applied Biosystems) with an initial denaturation of $96^{\circ} \mathrm{C}$ for $1 \mathrm{~min}$ followed by 25 cycles of denaturation at $96^{\circ} \mathrm{C}$ for $10 \mathrm{sec}$, $50^{\circ} \mathrm{C}$ for $5 \mathrm{sec}$ and $60^{\circ} \mathrm{C}$ for $1.15 \mathrm{~min}$ and a hold at $4^{\circ} \mathrm{C}$.

The sequence extension products were then mixed with Xterminator solution (10ul) and Sam solution (45 ul) from the Big Dye Xterminator purification kit (Life Technologies, Applied Biosystems) and analyzed by capillary electrophoresis on the ABI Gene Analyzer 3130xl (Life Technologies, Applied Biosystems). The sequence data was documented on electropherogram files and subjected to analysis by the data collection software package (Version 3.0).

The sequences from the two reactions were compared for quality assurance and aligned by ClustalW (Multiple Alignment Tool) to screen for all novel and/or mutations. Multiple sequence alignment among all samples and in comparison to the reference sequence revealed only three APOAI polymorphisms (rs670, rs5069 and rs1799837) out of the 11 reported variants in the Genbank databases. (http://www.ncbi.nlm.nih.gov/gene).

The genotypes of the APOAI rs670, rs5069 and rs17 99837 were also determined by sequence alignment with the published sequences [NCBI RefSeq: NT_033899.8] in the Genbank database for the promoter region of the APOAI employing BLAST sequence analysis (http://www. ncbi.nlm.nih.gov/gene).

\section{Statistical analysis of the association between the APOAI SNP's and serum lipid levels}

The allele and genotype frequencies were determined by simple gene-counting method for the polymorphisms including the APOAI rs670, rs5069 and rs1799837 and correlated with the individual phenotypic variables including serum lipid levels and documented family history of various complex diseases expressed as mean \pm SEM, median, interquartile range and percentage where appropriate (Table 1). Hardy-Weinberg equilibrium (HWE) was tested using the GENEPOP [39] software (Version 4.0.10) with significance at $\mathrm{p}<0.05$. The relation between APOAI 
variants and lipid levels were evaluated by the KruskalWallis ANOVA and the Mann-Whitney $U$ tests where appropriate and multiple linear regression, using SPSS (version 19.0). A two-tailed $\mathrm{p}<0.05$ was considered as statistically significant. Multivariate analysis using logistic regression was used to identify the predictor factors expressed by odds ratio (OR) with $95 \%$ confidence intervals using $\mathrm{R}$ software environment ( $\mathrm{R}$ Version 2.7.1) [40]. To estimate the power of the study, the sample size of 549 was analyzed using the Power and Sample Calculation Program (version 3.0.43) [41].

\section{Results}

\section{Sequence analysis and molecular screening}

The 435 nucleotide sequence which included a partial segment of the APOAI promoter region, 5'UTR, intron and exon 1 located between nucleotides -141 to +294 upstream of the human APOAI gene at contig nucleotide position 20270896 - 20270462 of chromosome 11 (Figure 1) was analyzed for all 549 samples and aligned with the reference sequence to genotype the three SNP's and to screen for putative polymorphisms. No novel SNP's were observed; the sequences obtained were deposited in the NCBI Genbank with accession number [GenBank: JX438706]. The most common genotypes observed for the APOAI rs670, rs5.69, rs1799837 polymorphisms were those for the homozygote wildtype allele (Table 2). The least common genotype for the rs670 polymorphism was homozygote AA (3.8\%) for the minor allele. Only one individual was observed with the homozygote TT for rs5069 while only three heterozygotes were observed for the rare allele rs1799837 and no homozygotes were identified. The allelic frequencies for all three SNP's were as follows: APOAI rs670G $=0.807 ;$ rs5069C $=0.964 ;$ rs1799837G = 0.997 . The genotype and allele frequencies at all three loci were found to be in HWE.

Association between the APOAI SNP's and serum lipid levels The relationship between genotype frequencies and serum levels of TC, TG, LDL-C and HDL-C are presented in

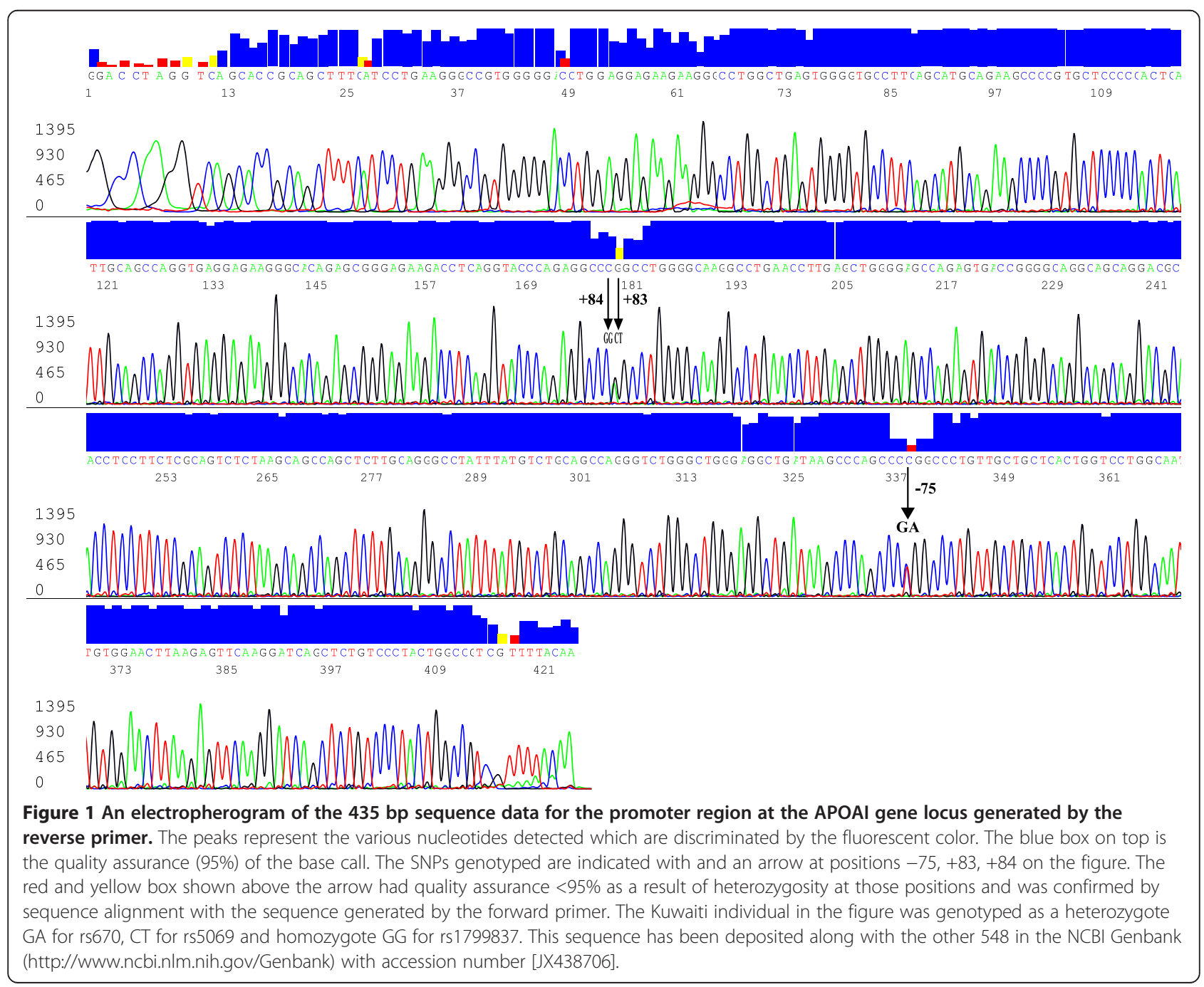




\begin{tabular}{|c|c|c|c|c|c|}
\hline SNP & Genotype & $\mathrm{n}$ & $\%$ & Allele & Allele frequency \\
\hline & GG & 358 & 65.20 & & \\
\hline \multirow[t]{3}{*}{ APOA1 rs670bp } & GA & 170 & 31.00 & G & 0.807 \\
\hline & AA & 21 & 3.80 & A & 0.193 \\
\hline & $\mathrm{CC}$ & 511 & 93.10 & & \\
\hline \multirow[t]{3}{*}{ APOA1 rs5069 } & $C T$ & 37 & 6.70 & C & 0.964 \\
\hline & $\pi$ & 1 & 0.20 & $\mathrm{~T}$ & 0.360 \\
\hline & GG & 546 & 99.45 & & \\
\hline \multirow[t]{2}{*}{ APOA1 rs1799837 } & GA & 3 & 0.55 & G & 0.997 \\
\hline & $\mathrm{AA}$ & 0 & 0 & $A$ & 0.003 \\
\hline
\end{tabular}

Figure 2. A significant association $(\mathrm{p}=0.02)$ was observed for the APOAI rs670 polymorphism with carriers of the A allele $(n=185)$ displaying higher LDL-C levels than individuals with the homozygote GG genotype $(\mathrm{n}=344)$ (Table 3$)$. An association ( $\mathrm{p}=0.03)$ was also found between the APOAI rs670 polymorphism and TC levels with carriers of the A allele $(n=191)$ displaying higher TC levels than individuals with homozygous GG genotype $(\mathrm{n}=358)$ (Table 3). Neither HDL nor TG were significantly associated $(\mathrm{p}>0.05)$. In a multivariate analysis using logistic regression the APOAI rs670 was found to be an independent predictive factor when controlling for age, sex and BMI for both TC and LDL-C levels with an odds ratio of 1.77 (95\% CI: 1.17-2.69, p=0.006) and 1.66 (95\% CI: $1.10-2.51 \mathrm{p}=0.014)$, respectively (Table 4). No significant association was observed between the genotypes of the APOAI rs5069 and rs1799837 polymorphisms with regards to all the parameters analyzed including serum lipid levels and family history of dyslipidemia (data not shown).

\section{Discussion}

The present study is the first to report sequence analysis of the APOAI promoter region in an Arab ethnic group among the Kuwaiti population. Previous studies on the association of APOAI polymorphisms and variation in serum lipid levels have relied mainly on PCR-RFLP profiling $[11,16,20,24,29,31,35]$ while a few studies have performed re-sequencing $[13,19,42,43]$. No novel sequences were observed in the sampled Kuwaiti population nor was the previously reported APOAI -27 polymorphism [13] in a Japanese boy, suggesting this one to be ethnic specific, not having been reported in many other populations. The other reported SNPs (CR991531, HR971651, rs12721302, rs372263101, rs199729971, rs141383703, rs3 68534370 and CS991294) in the target region sequenced were not identified in any of the Kuwaiti samples probably as a consequence of these SNPs being very rare $(<0.01)$ in a given population and could be ethnic specific. In addition, the absence of novel SNPs in the Kuwaiti population, comprising mainly of Arab ethnicity, could reflect the biological importance of conserving the promoter region and the 5 ' upstream sequence from the first transcription site at the APOAI gene locus. This would then ensure the integrity of its biological function in regulating APOAI gene expression, effecting regulation of gene expression of neighboring genes in the same cluster on chromosome 11, or influencing the expression of other apolipoprotein gene family. The integrity of the sequence upstream of the transcription site has also been reported to be essential to achieve sufficient expression of apoA-I $[42,44]$ as various mutations in the promoter region result in marked reduction of APOAI expression and serum protein levels [44]. Moreover, sequence analysis of the promoter region has allowed identification of polymorphisms to be associated with extremely low concentrations of HDL-C. Matsunaga et al. [13] showed that compound heterozygosity of mutations at the promoter region $(-27$ and -75$)$ resulted in significantly reduced levels of APOAI expression subsequently leading to reduced levels of apoA-I and HDL-C. Henakhaus et al. [43] also conducted sequence analysis of 94 South Asian immigrants in the USA and reported several polymorphisms in the APOAI gene (1683 bp), including the APOAI rs670. Specific hereditary patterns were common in this ethnic group, and that their frequencies were different from Europeans, suggesting the interaction of race and ethnicity on APOAI gene expression. Haase et al. [19] conducted a molecular analysis of the APOAI gene locus in over 10000 Danish individuals and reported a positive association between the APOAI -75 polymorphism and LDL and TC levels, and that homozygosity of APOAI rs670 A and heterozygosity of the APOAI rs5069 polymorphism were associated with increased HDL-C and apoA-I levels. This is consistent with our observation that the APOAI rs670 polymorphism is correlated with serum TC and LDL-C. In many of the studies reviewed, carriers of the minor A allele had significantly increased levels of LDL when compared with homozygote individuals with the wildtype $\mathrm{G}$ allele implicating it as a "risk" allele. On the other hand, our analysis of the APOAI rs670 and rs5069 genotypes with variation in HDL-C levels was in disagreement with Haase et al. [19] which may be due to the limitation in our sample size and ethnic variation. Several studies $[13,19,24,31,32,42,44]$ have reported inconsistent results with regard to the effect of the APOAI polymorphisms including rs670 on HDL-C levels and its actual association with serum lipid levels. In comparison, Daneshpour et al. [29] documented an association between APOAI haplotypes consisting of the A allele with variation in serum TC and LDL-C levels. It has been suggested that the A allele is not directly responsible for the associative effect on serum APOAI and HDL-C levels 

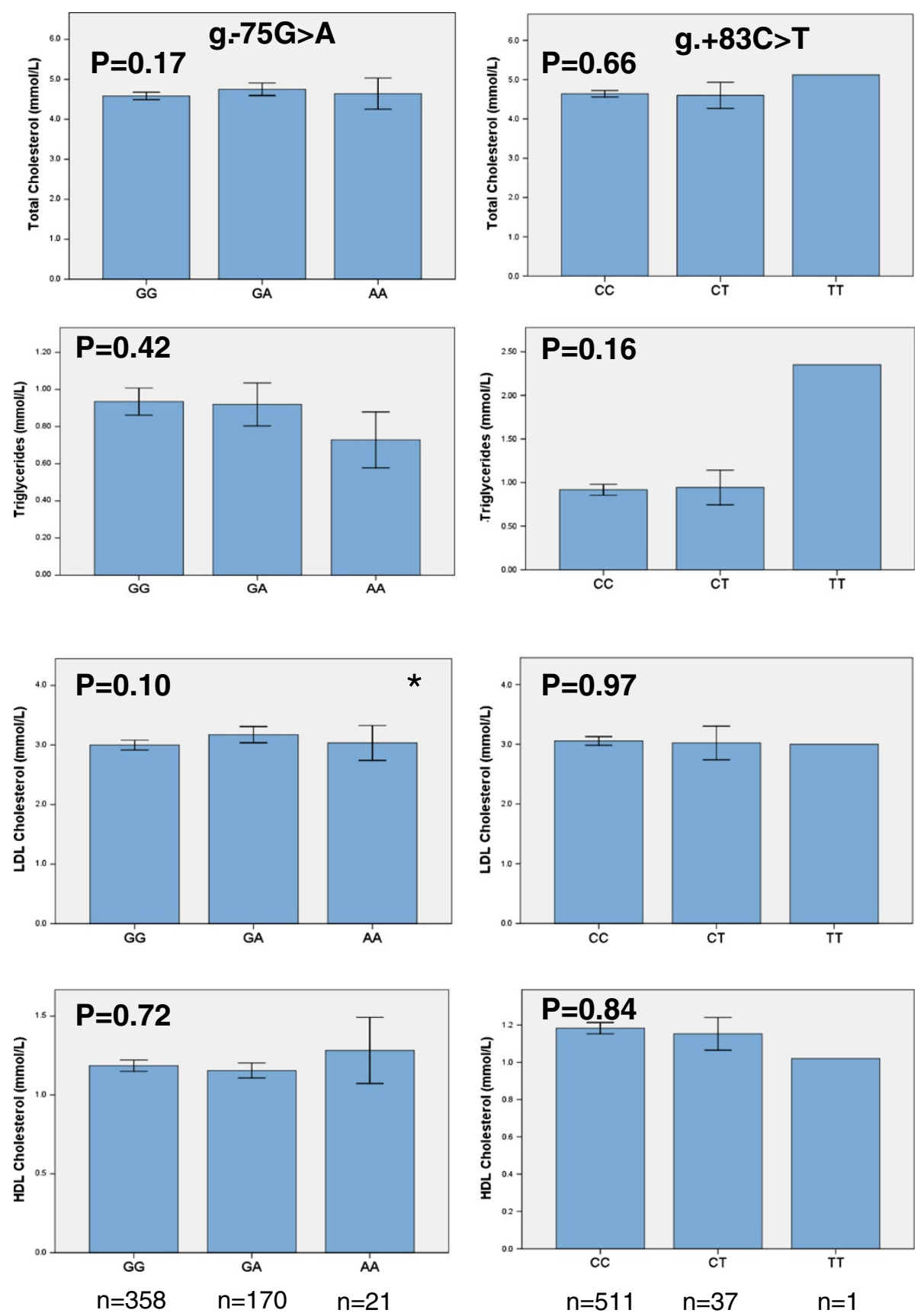

Figure 2 Mean lipid levels as function of two APOAI SNPs, rs670 (g.-75G > A) and the rs5069 (g. + 83C > T). Values shown are the mean \pm SEM. $p$ values were estimated according to Kruskal-wallis ANOVA and are shown. The Mann-Whitney $U$ test was used to compare wild type genotypes against heterozygous and mutant genotypes combined, ${ }^{*}, p<0.05$.

$[13,24]$ but rather is in play with other polymorphisms through linkage disequilibrium to regulate apoA-I levels [31] thereby affecting variation in serum HDL-C and TC levels. This may very well explain the results obtained in this study where carriers of the APOAI rs670 A allele were 1.77 times more at "risk" of increased TC levels $(\mathrm{p}=0.006)$ and 1.66 times more likely to have increased LDL-C $(p=0.014)$ than those with the GG genotype when controlling for age, sex and BMI in the Kuwaiti population. The biological importance of APOAI rs670 is in its creation of an inverted sequence repeat homologous to other functional regulatory elements; such a mutation could have an important effect on the regulation by transcriptional factors [42] that may also affect other gene loci. Furthermore, the positive association (60.2\% power calculation estimate with a $5 \%$ significance) observed between 
Table 3 Association of the APOAl rs670 (g.-75G > A) and the rs5069 (g. $+83 C>$ T) polymorphisms and lipid profiles

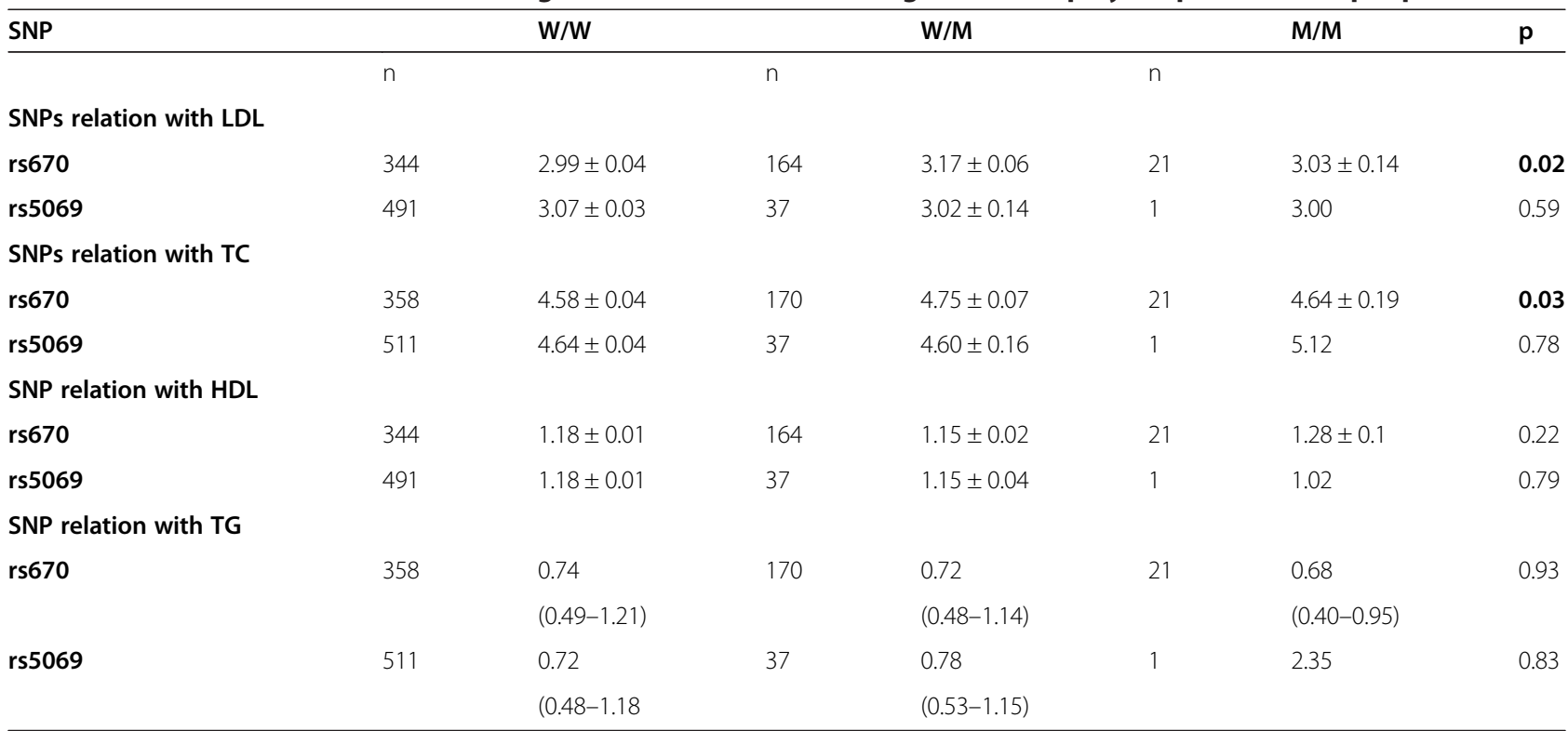

W/W, homozygous for common allele; W/M heterozygous for minor allele; M/M, homozygous for minor allele. The lipid level values are represented as mmol/L. Data shown as means \pm SEM or for the lipid levels except for TG where the median and inter-quartile range is represented. $p$ values were derived from multiple linear regressions with adjustment for sex, BMI and age assuming an additive genetic model. Significant values $(p<0.05)$ are shown in bold.

the APOAI rs670 and increased levels of LDL-C and TC, is more likely to be due to linkage disequilibrium with other polymorphisms in candidate and neighboring genes of lipid metabolism and/or transport such as APOB and LCAT which could be ethnic specific. This may somehow hinder the metabolism of LDL-C by the peripheral tissues leading to the failure of cholesterol esters entering the reverse cholesterol pathway and subsequently result in increased serum TC and LDL levels. However, no significant association was found with variation in lipid levels in the Kuwaiti population as indicated by the univariate

Table 4 Association of the APOAI rs670G > A genotype with total cholesterol and LDL-C

\begin{tabular}{|c|c|c|}
\hline Variable & OR $95 \% \mathrm{Cl}$ & P-value \\
\hline & \multicolumn{2}{|c|}{ A. Cholesterol grouped (High vs Normal) } \\
\hline APOA rs670 & $1.77(1.17-2.69)$ & 0.006 \\
\hline Age & $1.02(1.00-1.03)$ & 0.002 \\
\hline Sex & $1.12(0.74-1.70)$ & 0.579 \\
\hline \multirow[t]{2}{*}{ BMI } & $1.05(1.02-1.09)$ & 0.0004 \\
\hline & \multicolumn{2}{|c|}{ B. LDL grouped (Normal vs Abnormal) } \\
\hline APOA rs670 & $1.66(1.10-2.51)$ & 0.014 \\
\hline Age & $1.02(1.00-1.03)$ & 0.003 \\
\hline Sex & $1.77(1.18-2.65)$ & 0.005 \\
\hline BMI & $1.05(1.02-1.08)$ & 0.0006 \\
\hline \multicolumn{3}{|c|}{$\begin{array}{l}\text { The values represented include the odds ratio, confidence interval and } p \\
\text { values as evaluated by multivariate analysis using logistic regression in } 549 \\
\text { Kuwaiti individuals grouped based on their TC and LDL-C values according to } \\
\text { the population normal reference values. Multivariate analysis shows the APOAI } \\
\text { rs } 670 \text { to be a significant }(p<0.05) \text { independent predictive factor when } \\
\text { controlling for age, sex and BMI for both cholesterol and LDL levels. }\end{array}$} \\
\hline
\end{tabular}

analyses which is in consistent with others who did not observe an association between these changes that affect the MspI restriction site polymorphisms on HDL-C levels [32,45-49]. Wang et al. [16], however, reported a significant association of HDL-C with two SNPs (rs5069 and rs1799837) in which both were reported to be in linkage disequilibrium. Inconsistent results especially for the rs5069 and rs1799837 may sometimes arise from genotyping errors by PCR-RFLP due possibly to their adjacent positions as well as to several other factors. It has been suggested that the majority of the RFLPs are due to neutral mutations which probably do not directly affect the structure of the mature protein or the regulation of its neighboring genes [42]. This may also be the reason for the limited number of studies analyzing the +84 polymorphism. Nonetheless, this study further supports the designation of the APOAI rs1799837A allele as a "rare" allele.

The Kuwaiti population is heterogeneous comprised of a major Arab ethnic group including mostly bedouins, a minor Iranian ethnic group and admixes of other ethnicities [50]. Kuwait is a country that was first inhabited during the early $18^{\text {th }}$ century by Arab nomads and merchants migrating from the Arabian Peninsula, Mesopotamia and East Asia [50]. The origins of most of the current population of more than one million can be traced to three distinct regions now known as Saudi Arabia, Iran and Iraq comprising mainly Arabs whose ancestors were from the Arabian Peninsula and directly settled in Kuwait in the 19th century [50]. More recently, migrants from different parts of Asia (e.g. Jordan, Lebanon, and Syria, India) and 
North East Africa (e.g. Egypt and Greater Morocco) have also settled in Kuwait leading to increased admixture between the different subpopulations. Based on the analysis of the APOAI promoter region, the genetic contribution from each ethnic group into the Kuwaiti general gene pool is minimal that it doesn't appear to have made much difference in the distribution of the genotypes among the different subpopulations $(\mathrm{p}>0.05)$. Moreover, variation in lipid levels as a result of the contribution of other Arab ethnic groups in the Kuwaiti population is also minimal as the number of samples with such ethnicity is low $(<5 \%)$ therefore does not appear to have affected the normal distribution of TC, HDL and LDL levels. This makes it difficult to conduct analysis on the genotypes of such ethnic groups and their association to variation in HDL levels.

The genotype analysis of the three polymorphisms in the studied Kuwaiti population and in the two major ethnic groups showed the genotype and allele frequencies to be in HWE suggesting any positive finding to be more likely related to the biological function of the APOAI rs670 than to population stratification. In addition, the contribution made by the Kuwaiti-Iranian subpopulation $(22.77 \%)$ did not result in any significant difference to the overall population genotype frequency distribution. The allele frequency distribution at the three loci was compared to other reported populations (Table 5). The allelic frequency in the Kuwaiti population was found to be $19.3 \%$ at the APOAI rs670 which falls between the low $10 \%$ frequency reported for Africans [17] and for Iranians (13.8\%) [26] and the high 63.6\% in Chinese [11] while being approximately similar to those of Omani Arabs, Caucasian and Europeans (15-22\%) $[15,24,35]$ as well as being very close to the Danish [19]. However, the observed $+83 \mathrm{~T}$ frequency $(3.6 \%)$ is lower to the range of $5.1-7.8 \%$ reported for Omanis and Iranians $(18,27)$ and much lower than that of the African population (17) yet similar to the $3.5-4.0 \%$ reported in the Europeans Danes (19). The reported frequencies suggest demographic and gene flow patterns which need further investigation. Li et al. [20] also reported that variation in allelic frequencies at the APOAI rs670 between two subpopulations in China and the rare allelic frequency was different from Caucasians while being lower than in other oriental races suggesting the utility of this SNP in distinguishing various races. Those similar allelic frequencies could be attributed to a common ancestor homology. The inter-population sequence variation and allelic frequencies in the APOAI promoter region could variably modulate APOAI expression [16,19,22,23,32] subsequently leading to effects on serum lipid levels that manifest themselves in different ways in different populations. A GWA study conducted by the Global Lipids Genetic Consortium [51] in Europeans did not report any association of the three analyzed SNPs in the present study with variation in lipid levels as they were not covered by any of the microarray platforms used in the analysis. However, the study reported an association

Table 5 Comparison of the APOAI promoter rs670 and rs65069 allelic frequencies reported in this study with other populations

\begin{tabular}{|c|c|c|c|c|c|c|}
\hline \multirow[t]{2}{*}{ Population } & \multirow[t]{2}{*}{ Sample size } & \multicolumn{4}{|c|}{ SNP allele frequency } & \multirow[t]{2}{*}{ Reference } \\
\hline & & rs670 & & rs5069 & & \\
\hline & $\mathbf{n}$ & G & A & C & $\mathbf{T}$ & \\
\hline Africans (Nigeria) & 786 & 0.899 & 0.101 & 0.598 & 0.402 & Kamboh et al. [17] \\
\hline Caucasians & 243 & 0.779 & 0.221 & 0.959 & 0.041 & Wang et al. [16] \\
\hline Europeans & 1078 & 0.841 & 0.159 & & & Talmud et al. [24] \\
\hline \multirow[t]{2}{*}{ Europeans (Danish) } & $190 *$ & 0.810 & 0.190 & 0.965 & .035 & Haase et al. [19] \\
\hline & 10273 & 0.810 & 0.019 & 0.960 & .040 & \\
\hline French Canadians & 653 & 0.850 & 0.150 & & & Minnich et al. [31] \\
\hline Brazilians & 414 & & 0.180 & & & De Franca et al. [32] \\
\hline Chinese & 1030 & 0.364 & 0.636 & - & - & Yin et al. [11] \\
\hline Hei Yi Zhaung Chinese & 474 & 0.703 & 0.298 & - & - & Li et al. [20] \\
\hline Han Chinese & 564 & 0.660 & 0.340 & - & - & Li et al. [20] \\
\hline Hong Kong Chinese & 271 & 0.689 & 0.311 & 0.949 & 0.051 & Ma et al. [18] \\
\hline Japanese & 1880 & 0.844 & 0.156 & 0.922 & 0.078 & Shioji et al. [27] \\
\hline Iranian & 823 & 0.862 & 0.138 & 0.946 & 0.054 & Daneshpour et al. [29] \\
\hline Omanis & 150 & 0.783 & 0.217 & 0.933 & 0.067 & Al-Yahyaee et al. [35] \\
\hline Kuwaitis & 549 & 0.807 & 0.193 & 0.964 & 0.036 & Present study \\
\hline
\end{tabular}

*Based on re-sequencing of the APOAI promoter region [19]. 
with SNP rs964184 [51]. To investigate if the two studied SNPs (rs670 and rs5069) were in LD with the published SNP, the Proxy SNPs rs11216153 and rs7123326 used in the Hapmap and 1000genome data was used to tag the two SNPs. The analysis showed that rs964184 was not in LD with rs670 and rs5069 $\left(r^{2}=0.116\right.$ and $r^{2}=0.006$ respectively). Likewise, the rs9326246 recently published by the CardioGramplusC4D [52] cconsortium was tagged by another Proxy SNP rs7350481 and was found not to be in LD with rs11216153 and $\operatorname{rs} 7123326\left(\mathrm{r}^{2}=0.015\right.$ and $\mathrm{r}^{2}=0.005$ respectively).

\section{Conclusion}

In this study, three specific polymorphisms were genotyped by re-sequencing the APOAI promoter region including the common rs670 polymorphism along with the rare polymorphisms at the +83 and +84 loci in a single reaction, overcoming problems with genotyping errors frequently observed with PCR-RFLP. The present study showed that the Kuwaiti population could be genetically disposed to developing dyslipidemia in the presence of the APOAI rs670 polymorphism and other SNPs which need to be further investigated. Re-sequencing was found to be a more informative option, especially if inter-population variation and ethnicity have a role in the genetic association of the gene and its outcomes. With recent advances and the availability of high performance, cost effective automated gene analyzers such as Next-Generation sequencing, conducting high throughput genotyping and mutation screening of candidate genes in lipid metabolism and/or transport is highly recommended for different ethnic groups and in a larger sample size in order to better understand the differences in population frequencies, and to more accurately define "risk" and "protective" alleles from those which are simple variants. This will assist in the goal towards personalized and preventive medicine.

\section{Abbreviations \\ apoA-I: Apolipoproteinai protein; APOAl: Apolipoprotienai gene; APOB: Apolipoproteinb gene; BLAST: Basic local alignment search tool; BMI: Body mass index; DNA: Deoxyribonucleic acid; HDL-C: High-density- lipoprotein-cholesterol; LCAT: Lecithin cholesterolacyltransferase; LDL-C: Low-density lipoprotein-cholesterol; NCBI: National center for biotechnology information; OR: Odds ratio as estimated by logistic regression; PCR: Polymerase chain reaction; SNPs: Single nucleotide polymorphisms; TC: Total cholesterol; TG: Triglycerides.}

\section{Competing interests}

The authors declare there are no competing interests.

\section{Authors' contributions}

SA prepared the project proposal and study design, supervised the molecular genetic studies and sample collection and documentation, participated in the sequence alignment and analysis and drafted the manuscript. AA participated in the study design, carried out most of the statistical analysis and assisted in draft of the manuscript. BA carried out the molecular genetic techniques, sequencing and sequence alignment and participated in the manuscript draft. MA contributed to the study design, participated in the data analysis and edited the manuscript. GE facilitated sample collection and documentation of the clinical and phenotypic data and assisted with the lipid profile analysis. All the authors have read and approved the final manuscript.

\section{Acknowledgments}

This research was supported and funded by Kuwait University Research Administration, Project SL09/07. The authors would also like to acknowledge the General Facility Project (GS01/02) for the use of the ABI 3130xI Gene Analyzer. The authors extend their deepest appreciation and gratitude to all the participants in this study and to the statistical assistance provided by $\mathrm{Mr}$. Sriraman Devrajan at Dasman Diabetes Center, Dr. Thanaa Refai and the technical staff at the Clinical Laboratory in Al-Ameri Hospital, and to the technical staff at Al-Sabah Chest Hospital in Kuwait for their assistance with the blood collection and Lipid profile analysis. The authors would also like to thank Dr. Wafaa Al-Kandari for reviewing the discussion regarding the sequence analysis, Prof. Yunus Luqmani and Dr. Martha Thomson for editing the manuscript.

\section{Author details}

Department of Biological Sciences, Faculty of Science, Kuwait University, PO Box 5069, Safat 13060, Kuwait. '2Department of Molecular Pathology, Faculty of Medicine, Kuwait University, Safat, Kuwait. ${ }^{3}$ Yarmouk Clinic, Ministry of Health, Safat, Kuwait.

Received: 17 August 2012 Accepted: 10 September 2013 Published: 12 September 2013

\section{References}

1. Trayhurn P, Beattie JH: Physiological role of adipose tissue: white adipose tissue as an endocrine and secretory organ. Proc Nutr Soc 2001, 60(3):329-339.

2. Heller DA, de Faire U, Pedersen NL, Dahlen G, McClearn GE: Genetic and environmental influences on serum lipid levels in twins. N Eng J Med 1993, 328(16):1150-1156.

3. Boes E, Coassin S, Kollerits B, Heid IM, Kronenberg F: Geneticepidemiological evidence on genes associated with HDL cholesterol levels: a systematic in-depth review. Exp Gerontol 2009, 44(3):136-160.

4. Andreotti G, Menashe I, Chen J, Chang SC, Rashid A, Gao YT, Han TQ, Sakoda LC, Chanock S, Rosenberg PS, Hsing AW: Genetic determinants of serum lipid levels in Chinese subjects: a population-based study in Shanghai, China. Eur J Epidemiol 2009, 24(12):763-774.

5. Goode EL, Cherny SS, Christian JC, Jarvik GP, de Andrade M: Heritability of longitudinal measures of body mass index and lipid and lipoprotein levels in aging twins. Twin Res Hum Genet 2007, 10(5):703-711.

6. Breslow JL: Genetics of lipoprotein abnormalities associated with coronary artery disease susceptibility. Annu Rev Genet 2000, 34:233-254.

7. Horton JD, Cohen JC, Hobbs HH: Molecular biology of PCSK9: its role in LDL metabolism. Trends Biochem Sci 2007, 32(2):71-77.

8. Chasman DI, Paré G, Zee RY, Parker AN, Cook NR, Buring JE, Kwiatkowski DJ, Rose LM, Smith JD, Williams PT, Rieder MJ, Rotter Jl, Nickerson DA, Krauss RM, Miletich JP, Ridker PM: Genetic loci associated with plasma concentration of low-density lipoprotein cholesterol, high-density lipoprotein cholesterol, triglycerides, apolipoprotein A1, and Apolipoprotein B among 6382 white women in genome-wide analysis with replication. Circ Cardiovasc Genet 2008, 1(1):21-30.

9. Aulchenko YS, Ripatti S, Lindqvist I, Boomsma D, Heid IM, Pramstaller PP, Penninx BW, Janssens AC, Wilson JF, Spector T, Martin NG, Pedersen NL, Kyvik KO, Kaprio J, Hofman A, Freimer NB, Jarvelin MR, Gyllensten U, Campbell H, Rudan I, Johansson A, Marroni F, Hayward C, Vitart V, Jonasson I, Pattaro C, Wright A, Hastie N, Pichler I, Hicks AA, et al: Loci influencing lipid levels and coronary heart disease risk in 16 European population cohorts. Nat Genet 2009, 41(1):47-55.

10. Miljkovic I, Yerges-Armstrong LM, Kuller LH, Kuipers AL, Wang X, Kammerer CM, Nestlerode CS, Bunker CH, Patrick AL, Wheeler WW, Evans RW, Zmuda $J M$ : Association analysis of 33 lipoprotein candidate genes in multi-generational families of African ancestry. J Lipid Res 2010, 51(7):1823-1831.

11. Yin RX, Li YY, Liu WY, Lai CQ: Apolipoprotein Al/C3/A5 haplotypes and serum lipid levels. Lipids Health Dis 2011, 10:140. 
12. Fielding CJ, Fielding PE: Molecular physiology of reverse cholesterol transport. J Lipid Res 1995, 36:211-228.

13. Matsunaga A, Sasaki J, Han H, Huang W, Kugi M, Koga T, Ichiki S, Shinkawa T, Arakawa K: Compound heterozygosity for an apolipoprotein A1 gene promoter mutation and a structural nonsense mutation with apolipoprotein A1 deficiency. Arterioscler Thromb Vasc Biol 1999, 19(2):348-355.

14. Herron KL, Lofgren IE, Adiconis X, Ordovas JM, Fernandez ML: Associations between plasma lipid parameters and APOC 3 and APOA4 genotypes in a healthy population are independent of dietary cholesterol intake. Atherosclerosis 2006, 184(1):113-20.

15. Angotti $E$, Mele E, Costanzo F, Awedimento EV: A polymorphism (G->A transition) in the -78 position of the apolipoprotein A-I promoter increases transcription efficiency. J Bio/ Chem 1994, 269(26):17371-17374.

16. Wang XL, Badenhop R, Humphrey KE, Wilcken DE: New Mspl polymorphism at $+83 \mathrm{bp}$ of the human apolipoprotein $\mathrm{Al}$ gene: association with increased circulating high density lipoprotein cholesterol levels. Genetic Epidemiology 1996, 13(1):1-10.

17. Kamboh MI, Bunker CH, Aston CE, Nesterlode CS, McAllister AE, Ukoli FA: Genetic association of five apolipoprotein polymorphisms with serum lipoprotein-lipid levels in African blacks. Genet Epidemiol 1999, 16:205-222.

18. Ma YQ, Thomas GN, Tomlinson B: Association of two apolipoprotein A-I gene Mspl Polymorphisms with lipid and blood pressure levels. Int J Cardiol 2005, 102:309-314.

19. Haase CL, Tybjærg-Hansen A, Grande P, Frikke-Schmidt R: Genetically elevated Apolipoprotein A-I, high-density lipoprotein cholesterol levels, and risk of ischemic heart disease. J Clin Endocrinol Metab 2010, 95(12):E500-E510.

20. Li Y, Yin R, Zhou Y, Deng Y, Yang D, Pan S, Lin W: Associations of the apolipoprotein $A-I$ gene polymorphism and serum lipid levels in the Guangxi Hei Yi Zhuang and Han populations. Int J Mol Med 2008, 21(6):753-764

21. Toptas B, Görmüş U, Ergen A, Gürkan H, Keleşoglu F, Darendeliler F, Bas F, Dalan AB, Izbirak G, Isbir T: Comparison of lipid profiles with APOA1 Mspl polymorphism in obese children with hyperlipidemia. In Vivo 2011, 25(3):425-430.

22. Tuteja R, Tuteja N, Melo C, Casari G, Baralle FE: Transription efficiency of human apolipoprotein A-I promoter varies with naturally occurring $A$ to G transition. FEBS Lett 1992, 304:98-101.

23. Danek GM, Valenti M, Baralle FE, Romano M: The A/G polymorphism in the -78 position of the apolipoprotein A-I promoter does not have a direct effect on transcriptional efficiency. Biochim Biophys Acta 1998, 1398:67-74.

24. Talmud PJ, Ye S, Humphries SE: Polymorphism in the promoter region of the apolipoprotein Al gene associated with differences in apolipoprotein Al levels: the European atherosclerosis research study. Genet Epidemiol 1994, 11(3):265-280

25. Moriyama K, Sasaki J, Takada Y, Matsunaga A, Fukui J, Albers JJ, Arakawa K: A cysteine containing truncated apolipoprotein A-I associated with high density lipoprotein deficiency. Arterioscler Thromb Vasc Biol 1996, 16:1416-1423.

26. Miccoli R, Bertolotto A, Navalesi R, Odoguardi L, Boni A, Wessling J, Funke $H$, Wiebusch $\mathrm{H}$, Eckardstein A, Assmann G: Compound heterozygosity for a structural apolipoprotein A-I variant, apo A-I(L141R)Pisa, and an apolipoprotein A-I null allele in patients with absence of HDL cholesterol, corneal opacifications, and coronary heart disease. Circulation 1996, 94(7):1622-1628.

27. Shioji K, Mannami T, Kokubo Y, Goto Y, Nonogi H, Iwai N: An association analysis between ApoA1 polymorphisms and the high-density lipoprotein (HDL) cholesterol level and myocardial infarction (MI) in Japanese. J Hum Genet 2004, 49(8):433-439.

28. Heng CK, Low PS, Saha N: Variations in the promoter region of the apolipoprotein A-1 gene influence plasma lipoprotein(a) levels in Asian Indian neonates from Singapore. Pediatr Res 2001, 49(4):514-518.

29. Daneshpour MS, Faam B, Mansournia MA, Hedayati M, Mesbah-Namin SA, Shojaei S, Zarkesh M, Azizi F: Haplotype analysis of ApoAl-CIII-AIV gene cluster and lipids level: tehran lipid and glucose study. Endocrine 2012, 41(1):103-110

30. Mar R, Pajukanta P, Allayee H, Groenendijk M, Dallinda-Thie G, Krauss RM, Sinsheimer JS, Cantor RM, de Bruin TW, Lusis AJ: Association of the APOLIPOPROTEIN A1/C3/A4/A5 gene cluster with triglyceride levels and LDL particle size in familial combined hyperlipidemia. Circ Res 2004, 94:993-999.
31. Minnich A, DeLangavant G, Lavigne J, Roederer G, Lussier-Cacan S, Davignon J: G-> A substitution at position -75 of the apolipoprotein A-I gene promoter. Evidence against a direct effect on HDL cholesterol levels. Arterioscler Thromb Vasc Biol 1995, 15(10):1740-1745.

32. De Franca E, Alves JG, Hutz MH: APOA1/C3/A4 gene cluster variability and lipid levels in Brazilian children. Braz J Med Biol Res 2005, 38(4):535-541.

33. Hamon SC, Kardia SLR, Boerwinkle E, Liu K, Klos KL, Clark AG, Sing CF: Evidence for consistent intragenic and intergenic interactions between SNP effects in the APOA1/C3/A4/A5 Gene cluster. Hum Hered 2006, 61(2):87-96.

34. Johansen K, Dunn B, Tan JC, Kwassi AA, Skotnicki A, Skotnicki M: Coronary artery disease and apolipoprotein AI-CIII gene polymorphism: a study of Saudi Arabians. Clin Genet 1991, 39(1):1-5

35. Al-Yahyaee SA, Al-Kindi MN, Al-Bahrani Al: Apolipoprotein A1 gene polymorphisms at the $-75 \mathrm{bp}$ and +83 / 84 bp polymorphic sites in healthy Omanis compared with world populations. Hum Biol 2004, 76(2):307-312.

36. Olusi SO, Al-Awadi AM, Abraham M: Baseline population survey data on the prevalence of risk factors for coronary artery disease among Kuwaitis aged 15 years and older. Ann Saudi Med 2003, 23(3-4):162-166.

37. Al Rashdan I, Al Nesef Y: Prevalence of overweight, obesity, and metabolic syndrome among adult Kuwaitis: results from community-based national survey. Angiology 2010, 61(1):42-48.

38. Miller SA, Dykes DD, Polesky HF: A simple salting-out procedure for extracting DNA from human nucleated cells. Nucleic Acids Res 1988, 16(3):1215

39. Raymond M, Rousset F: GENEPOP (version 1.2): population genetics software for exact tests and ecumenicism. J Hered 1995, 86:248-249.

40. R-development-core-team: R: a language and environment for statistical computing. R Foundation for statistical Computing 2010, Faul F, Erdfelder E, Lang AG, Buchner A: G*Power 3: A flexible statistical power analysis program for the social, behavioral, and biomedical sciences. Behav Res Methods 2007, 39:175-191.

41. Dupont WD, Plummer WD Jr: Power and sample size calculations: a review and computer program. Control Clin Trials 1990, 11:116-128.

42. Pagani F, Sidoli A, Giudici GA, Barenghi L, Vergani C, Baralle FE: Human apolipoprotein A-I gene promoter polymorphism: association with hyperalphalipoproteinemia. J Lipid Res 1990, 31(8):1371-1377.

43. Henkhaus RS, Dodani S, Manzardo AM, Butler MG: APOA1 gene polymorphisms in the South Asian immigrant population in the United States. Indian J Hum Genet 2011, 17(3):194-200.

44. Smith JD, Brinton EA, Breslow JL: Polymorphism in the human apolipoprotein A-I gene promoter region: association of the minor allele with decreased production rate in vivo and promoter activity in vitro. J Clin Invest 1992, 89:1796-1800.

45. Kamboh MI, Aston CE, Nestlerode CM, Mcallister AE, Hamman RF: Haplotype analysis of two ApoA1/Mspl polymorphisms in relation to plasma levels of apoA-I and HDL-cholesterol. Atherosclerosis 1996, 127(2):255-262.

46. Larson IA, Ordovas JM, Barnard JR, Hoffmann MM, Feussner G, Lamon-Fava S, Schaefer EJ: Effects of apolipoprotein A-I genetic variations on plasma apolipoprotein, serum lipoprotein and glucose levels. Clinical Genetics 2002, 61(3):176-184.

47. Brown CM, Rea TJ, Hamon SC, Hixson JE, Boerwinkle E, Clark AG, Sing CF: The contribution of individual and pairwise combinations of SNPs in the APOA1 and APOC3 genes to interindividual HDL-C variability. J Mol Med (Berl) 2006, 84(7):561-572

48. Boekholdt SM, Souverein OW, Tanck MW, Hovingh GK, Kuivenhoven JA, Peters Rl, Jansen H, Schiffers PM, van der Wall EE, Doevendans PA, Reitsma $\mathrm{PH}$, Zwinderman $\mathrm{AH}$, Kastelein JJ, Jukema JW: Common variants of multiple genes that control reverse cholesterol transport together explain only a minor part of the variation of HDL cholesterol levels. Clin Genet 2006, 69(3):263-270.

49. Haase CL, Tybjærg-Hansen A, Qayyum AA, Schou J, Nordestgaard BG, FrikkeSchmidt R: LCAT, HDL cholesterol and ischemic cardiovascular disease: a Mendelian randomization study of HDL cholesterol in 54,500 individuals. J Clin Endocrinol Metab 2012, 97(2):E248-E256.

50. Al-Bustan SA, Alnaqeeb MA, Annice BG, Ibrahim G, Al-Rubaian J, Ahmed AH, Refai TM: Apolipoprotein E genotyping among the healthy Kuwaiti population. Hum Biol 2005, 77(4):487-498.

51. Teslovich TM, Musunuru K, Smith AV, Edmondson AC, Stylianou IM, Koseki M, Pirruccello JP, Ripatti S, Chasman DI, Willer CJ, Johansen CT, Fouchier SW, 
Isaacs A, Peloso GM, Barbalic M, Ricketts SL, Bis JC, Aulchenko YS,

Thorleifsson G, Feitosa MF, Chambers J, Orho-Melander M, Melander O, Johnson T, Li X, Guo X, Li M, Shin Cho Y, Jin Go M, Jin Kim Y, Lee JY, Park T, et al: Biological, clinical and population relevance of 95 loci for blood lipids. Nature 2010, 466(7307):707-713.

52. CARDloGRAMplusC4D Consortium, Deloukas $P$, Kanoni S, Willenborg $C$ Farrall M, Assimes TL, Thompson JR, Ingelsson E, Saleheen D, Erdmann J, Goldstein BA, Stirrups K, König IR, Cazier JB, Johansson A, Hall AS, Lee JY, Willer CJ, Chambers JC, Esko T, Folkersen L, Goel A, Grundberg E, Havulinna AS, Ho WK, Hopewell JC, Eriksson N, Kleber ME, Kristiansson K, Lundmark P, Lyytikäinen LP, et al: Large-scale association analysis identifies new risk loci for coronary artery disease. Nat Genet 2013, 45(1):25-33.

doi:10.1186/1471-2350-14-90

Cite this article as: Al-Bustan et al:: Re-sequencing of the APOAI

promoter region and the genetic association of the $-75 \mathrm{G}>\mathrm{A}$

polymorphism with increased cholesterol and low density lipoprotein

levels among a sample of the Kuwaiti population. BMC Medical Genetics 2013 14:90

\section{Submit your next manuscript to BioMed Central and take full advantage of:}

- Convenient online submission

- Thorough peer review

- No space constraints or color figure charges

- Immediate publication on acceptance

- Inclusion in PubMed, CAS, Scopus and Google Scholar

- Research which is freely available for redistribution 